ARTICLE

\title{
The origin of the particle-size-dependent selectivity in 1-butene isomerization and hydrogenation on $\mathrm{Pd} / \mathrm{Al}_{2} \mathrm{O}_{3}$ catalysts
}

\author{
Alexander Genest (10) 1,2,5, Joaquín Silvestre-Albero (10) 1,4,5, Wen-Qing Li ${ }^{2,5}$, Notker Rösch (1) ${ }^{1,3}$ \& \\ Günther Rupprechter (i) ${ }^{1 凶}$
}

The selectivity of 1-butene hydrogenation/isomerization on Pd catalysts is known to be particle size dependent. Here we show that combining well-defined model catalysts, atmospheric pressure reaction kinetics, DFT calculations and microkinetic modeling enables to rationalize the particle size effect based on the abundance and the specific properties of the contributing surface facets.

\footnotetext{
${ }^{1}$ Institute of Materials Chemistry, Technische Universität Wien, Getreidemarkt 9/BC, A-1060 Vienna, Austria. ${ }^{2}$ Institute of High Performance Computing, Agency for Science, Technology and Research, 1 Fusionopolis Way, \#16-16 Connexis, Singapore 138632, Singapore. ${ }^{3}$ Department Chemie and Catalysis Research Center, Technische Universität München, D-85747 Garching, Germany. ${ }^{4}$ Present address: Laboratorio de Materiales Avanzados, Departamento de Química Inorgánica-IUMA, Universidad de Alicante, E-03690 San Vicente del Raspeig, Spain. ${ }^{5}$ These authors contributed equally: Alexander Genest, Joaquín

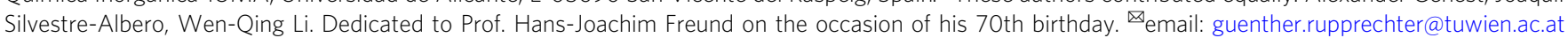


O lefinic hydrocarbons constitute valuable key building blocks in the chemical industry, that are used for a wide range of products, including solvents, coatings, and polymers $^{1-5}$. Selective hydrogenation and hydroisomerization are thus critical steps in upgrading refinery streams. Butenes are a distinct example: 2-butenes and isobutene are desirable for high octane gasoline, whereas 1-butene is important in polymer chemistry $^{6}$. In view of the recently increased price of olefinic hydrocarbons (resulting from the "olefin gap"), there is a strong industrial interest in manufacturing specific isomers ${ }^{6}$. This highlights the importance of selectivity when carrying out isomerization, while avoiding hydrogenation to less valuable products. Note that both types of transformations involve hydrogen addition and are catalyzed by the very same $\mathrm{Pd} / \mathrm{Al}_{2} \mathrm{O}_{3}$ catalyst. Hydrogenation and isomerization of 1-butene may proceed via a common (hydrogenated) 2-butyl intermediate ${ }^{7,8}$, but isomerization is also possible via an initial dehydrogenation, that does not directly facilitate hydrogenation, cf. Fig. 1. Based on a recent combined experimental and theoretical study of Pd single crystals, the second route was identified as being preferred ${ }^{9}$. The catalyst performance can be tuned via the size dependent properties of the metal nanoparticles, that affect reactivity in different ways. The size-dependent electronic structure of clusters and nanoparticles has been intensively discussed ${ }^{10-19}$, but the combination of specific facets (characterized via their generalized coordination number) is equally important. ${ }^{20-34}$.

In this work, based on 1-butene as example, we study the effects of particle size on both kinds of reactions, hydrogenation and isomerization. We combine experiment and modeling to discern factors influencing both routes using well characterized model catalyst particles. A crucial factor to understand the selectivity will be the type and roughness of the Pd nanoparticle facets.

\section{Results}

$\mathbf{P d} / \mathrm{Al}_{2} \mathrm{O}_{3}$ model catalysts. To examine the selectivity of the catalyst, we resorted, once again, to a "surface science" model catalyst approach, combined with high pressure cell kinetic tests and theoretical modeling, for details see Supplementary Notes 1-3 of the Supplementary Information (SI). Pd nanoparticles (NPs) were grown impurity-free on $\mathrm{Al}_{2} \mathrm{O}_{3}$ model supports under clean ultrahigh vacuum (UHV) conditions, with exact control over the nucleation density (number of Pd NPs/ $\mathrm{cm}^{2}$; via the substrate temperature) and the $\mathrm{Pd}$ amount (number of $\mathrm{Pd}$ atoms $/ \mathrm{cm}^{2}$; via the evaporation dose measured by a quartz microbalance). Thus, the mean Pd particle size (or the number of $\mathrm{Pd}$ atoms/NP) in the systems under study is well defined.

The structural characteristics of the support and the Pd NPs have previously been examined in detail by H.-J. Freund's group

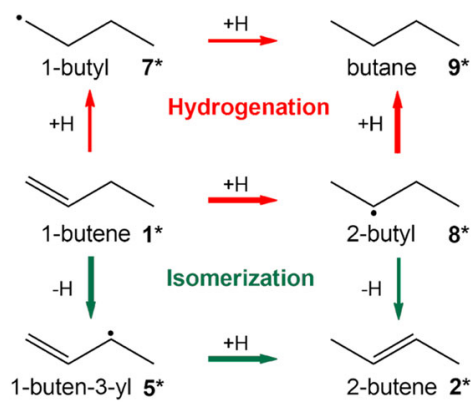

Fig. 1 Reaction network for 1-butene isomerization, green, and hydrogenation, red, on Pd catalysts. Hydrocarbon species are identified using bold numbers consistent with ref. ${ }^{8}$. using an array of surface-sensitive methods (see the SI) ${ }^{35-40}$. Here, we deliberately prepared Pd NPs with a mean size of $2-8 \mathrm{~nm}$, so that all NPs essentially exhibit bulk electronic structure, i.e., they are in the "scalable" regime ${ }^{10,15-17}$. Thus, variations of the electronic structure, that small Pd clusters (with less than 80 atoms) may exhibit ${ }^{16}$, are not to be expected. Given that $\mathrm{Al}_{2} \mathrm{O}_{3}$ is a rather inert support, metal/oxide boundary effects may be largely excluded, so that the reactivity can be solely assigned to the Pd NPs; the pure support did not show any reactivity.

Resulting from the current preparation conditions, $\mathrm{Pd}$ nanocrystals larger than $4 \mathrm{~nm}$ are well-developed truncated cuboctahedra (according to scanning tunneling microscopy $(\mathrm{STM}))^{41-44}$, mainly exposing (111) and (100) surface facets (Fig. 2a; further characterized by infrared (IR) spectra of adsorbed hollow, bridge and on-top $\mathrm{CO}^{38,45-47}$, agreeing well with corresponding wet-chemically prepared catalysts $)^{48-51}$. The lowindex facets may exhibit few steps and are terminated by edges. The Pd nanocrystals with a mean size below $4 \mathrm{~nm}$ typically show round/irregular outlines in STM and have rough stepped surfaces (cf. Fig. 2c; again confirmed by stronger or even dominating ontop CO peaks in IR). For preparation and structure details, see Supplementary Note 3 of the SI.

Kinetic tests at atmospheric pressure. After UHV preparation, the various $\mathrm{Pd} / \mathrm{Al}_{2} \mathrm{O}_{3}$ model catalysts (mean NP diameter from $2 \mathrm{~nm}$ to $8 \mathrm{~nm}$ ) were transferred in UHV to a "high-pressure" reaction cell ${ }^{52}$, where batch reactor kinetic studies of 1-butene isomerization and hydrogenation were carried out at atmospheric pressure. Reaction conditions were chosen to avoid $\beta$-Pd-hydride formation. Reactant and product analysis by gas chromatography as a function of reaction time enabled us to determine catalytic rates (turnover frequencies) and selectivity over ensembles of specific, rather uniform particle sizes. Given that only weakly adsorbing reactants are used, we do not expect restructuring of the particles as seen in $\mathrm{CO}$ or oxygen or under high vacuum ${ }^{53,54}$, especially not within $10 \mathrm{~min}$ after which we evaluated the TOFs. For details of the kinetic measurements, see the SI.

Figure 3 shows the 1-butene conversion as a function of the total number of Pd surface atoms in the catalyst samples, exactly

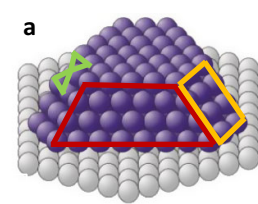

Well faceted particle $>4 \mathrm{~nm}$

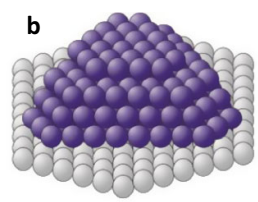

Hybrid particle $\sim 4 \mathrm{~nm}$

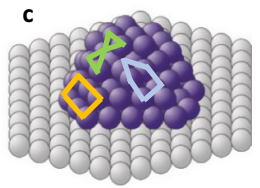

Rough particle $<4 \mathrm{~nm}$

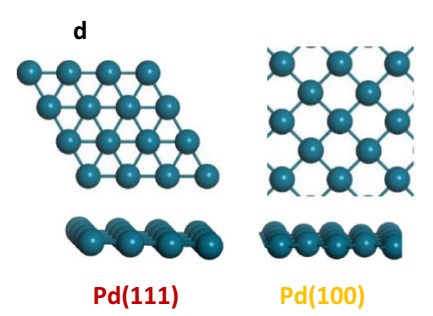

Flat surfaces

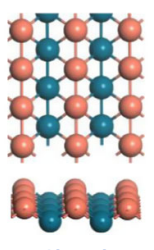

$\operatorname{Pd}(110)$

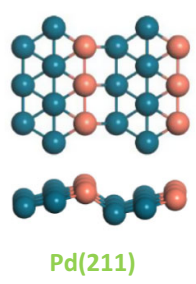

Fig. 2 Schematics of Pd nanoparticles as catalysts by combining smooth and stepped single crystal surfaces. a Large particles carry extended patches of smooth surfaces, modeled by selected facets. b "Hybrid" particle of larger size with rougher surface. c Smaller rough nanoparticle. d Ball and stick models of the smooth surfaces $\mathrm{Pd}(111)$ and $\mathrm{Pd}(100)$, and the rougher surfaces Pd(110) and Pd(211). 


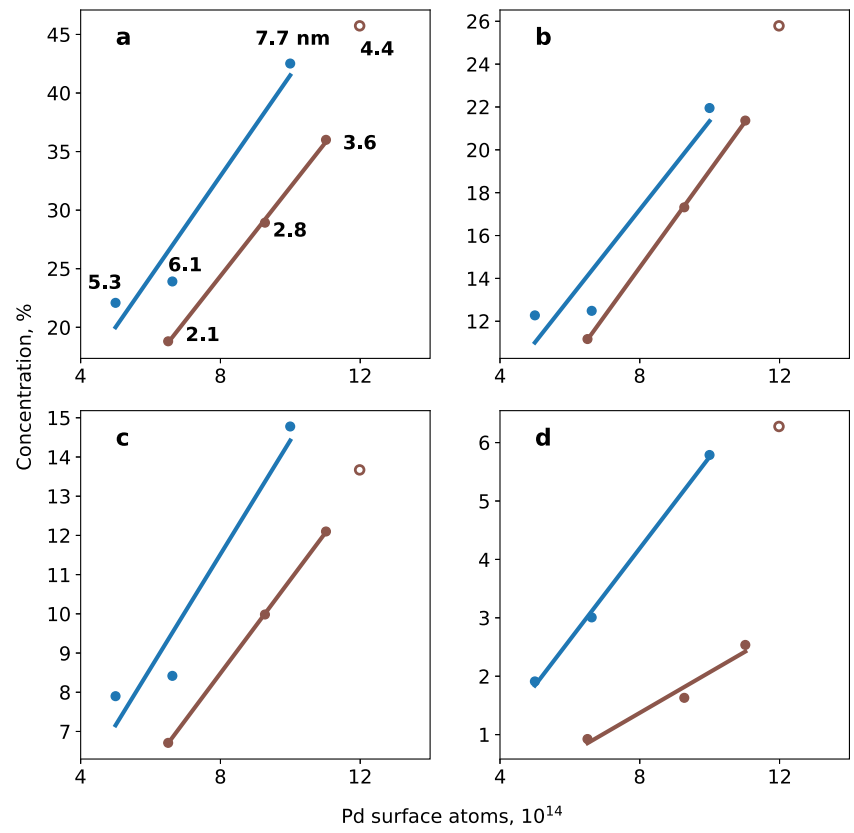

Fig. 3 Composition of the gas phase in the reaction cell at $373 \mathrm{~K}$ after $10 \mathrm{~min}$. Isomerization and hydrogenation of 1-butene on various $\mathrm{Pd} / \mathrm{Al}_{2} \mathrm{O}_{3} /$ $\mathrm{NiAl}(110)$ model catalysts, over NPs with smooth (blue) and rough (brown) surfaces; average particle diameters $(\mathrm{nm})$ indicated in panel a. Shown are the fractions (in percent) as a function of the total number of Pd surface atoms: a converted reactant 1-butene, as well as products $\mathbf{b}$ trans-2-butene, c cis-2-butene, and $\mathbf{d}$ n-butane; see also the SI. Also shown are the results for NPs of $4.4 \mathrm{~nm}$ diameter, in between both regimes (brown circles; see text). Initial state: $\mathrm{P}_{1 \text {-butene }}: 5 \mathrm{mbar} ; \mathrm{P}_{\mathrm{H} 2}: 10 \mathrm{mbar} ; \mathrm{Ar}$ added to 1 bar.

known from combining microbalance and STM data. For both the small/rough Pd particles (Fig. 3a, brown line) and the larger/ faceted Pd particles (Fig. 3a, blue line), the conversion of 1-butene scales linearly with the number of Pd surface atoms, but the larger particles are still more active, as shown by a constant shift of $\sim 8$ $\%$, that clearly indicates an effect of surface roughness. The same holds true for the yields of trans-2-butene (Fig. 3b), cis-2-butene (Fig. 3c) and n-butane (Fig. 3d), although for the latter the notably different slopes indicate variations in the selectivity ratio, depending on the surface roughness.

Figure 4a displays the particle size dependence of the turnover frequencies (TOFs, equivalent to the corresponding reaction rates measured/calculated after $10 \mathrm{~min}$ ) per $\mathrm{Pd}$ surface atom: for details, see the SI. The isomerization of 1-butene (green markers) shows only a very weak size dependence, whereas the hydrogenation of 1-butene (red) is clearly preferred on Pd NPs of $>4 \mathrm{~nm}$. According to our computational modeling (see below), we attribute the latter to the smoother facets of the (111) type. The selectivity ratio (represented by the isomerization/hydrogenation ratio) thus ranges from 18 on smaller Pd NPs to 5 on the group of larger faceted Pd NPs, for which it is rather constant (Fig. 4b). The trend change in selectivity ratio with particle size is a direct result of the difference in slope for hydrogenation over particles $<4 \mathrm{~nm}$ compared to larger particles, cf. Fig. $3 \mathrm{~d}$. The total average catalytic activity (1-butene consumption) for Pd NPs is very similar and close to $38 \mathrm{~s}^{-1}$; for details, see the SI. Modeling results that are used in a microkinetic model for various surfaces and subsequently combined to represent nanoparticles, see below, convincingly capture the trends of the TOF for hydrogenation (red inverted triangles), while the analogous isomerization results (green inverted triangles) scatter more. Despite the challenging nature of predicting TOFs and focusing the density functional
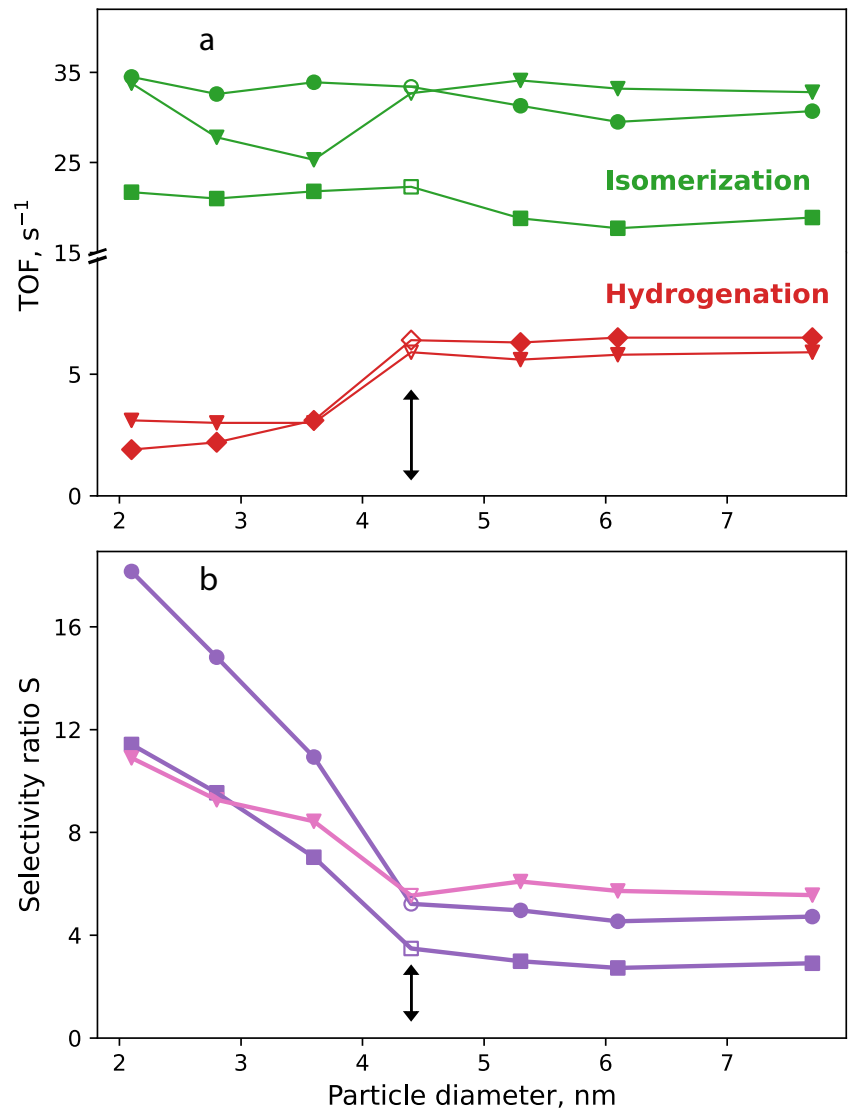

Fig. 4 Catalytic performance of $\mathrm{Pd} / \mathrm{Al}_{2} \mathrm{O}_{3} / \mathrm{NiAl}(110)$ catalysts as a function of the average size of the Pd NPs. a Turnover frequencies (TOFs) of isomerization (green) and hydrogenation (red) of 1-butene at $373 \mathrm{~K}$ and b selectivity ratio $S$, of TOFs of isomerization vs. hydrogenation from experiment (purple) or modeling (pink). Data points from experiment (trans + cis-2-butene-discs, trans-2-butene-squares, n-butanediamond), and modeling (inverted triangles); special case of $4.4 \mathrm{~nm}$ labeled by empty symbols, all other data represented by solid markers. Double arrows indicate the trend change in selectivity ratio. Modeling of isomerization focused on the trans-2-butene isomer.

theory (DFT) efforts solely on trans-2-butene, the modeling results represent quite well the overall experimental trends, including the selectivity ratio. As electronic structure and support effects can be excluded here, the different catalytic behavior has to originate from variations in the specific surface structure of the Pd NPs.

Modeling. To rationalize the molecular origin of the particle size dependent selectivity ratio, we carried out density functional theory (DFT) calculations on slab models using the generalized gradient approximation (GGA) in the PBE variant ${ }^{55}$; for details, see Supplementary Notes 1 and 2 of the SI. The larger wellfaceted Pd NPs were described by periodic models of the smooth surfaces $\operatorname{Pd}(111)$ and $\operatorname{Pd}(100)$, as well as $\operatorname{Pd}(211)$ representing edge sites, whereas for the surfaces of the smaller, rougher Pd NPs we chose periodic models of the surfaces $\operatorname{Pd}(211), \operatorname{Pd}(110)$ and $\operatorname{Pd}(100)$ (Fig. 2); the (211) surface is stepped. Steps and edges increase the hydrocarbon binding energies and may serve as adsorption sites in experiments. Similar to our previous report ${ }^{9}$, the adsorption modes, free energies, and activation energies were calculated for all four types of surfaces; detailed results are provided as SI. The preferred reaction pathways were identified from these DFT results, Fig. 1. 


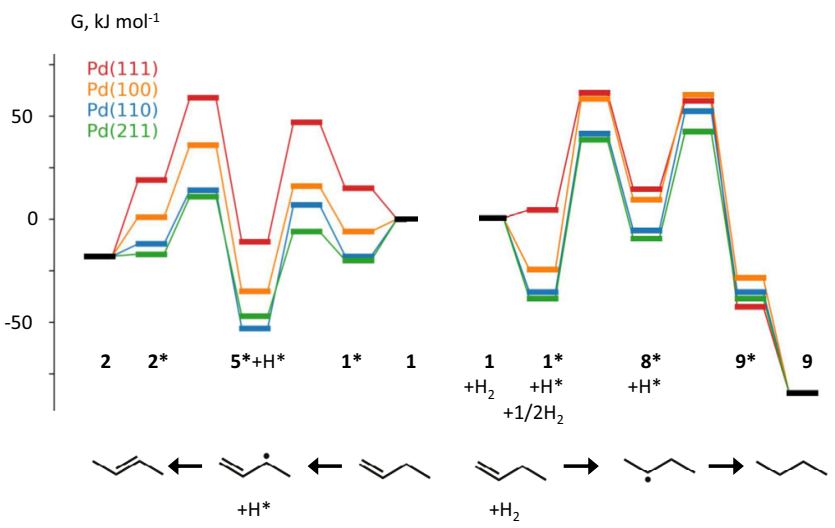

Fig. 5 Calculated free energy profiles of the transformations of 1-butene, 1: isomerization (to the left) vs. hydrogenation (to the right). Lowest energy pathways only. For easy comparability of isomerization and hydrogenation, we start at the center with 1-butene $\mathbf{1}$ in the gas phase that adsorbs on $\mathrm{Pd}(111)$ (red), $\mathrm{Pd}(100)$ (orange), $\mathrm{Pd}(110)$ (blue), and $\mathrm{Pd}(211)$

(green). The isomerization of $\mathbf{1}$ to 2 -butene, $\mathbf{2}$, starts with a dehydrogenation of $\mathbf{1}$ to 1-buten-3-yl $\mathbf{5}$ and co-adsorbed $\mathrm{H}^{*}$. As reference of this transformation, we use the free energy value of 1-butene $\mathbf{1}$ in the gas phase at $373 \mathrm{~K}, 100 \mathrm{kPa}$; the partial pressure values were $\mathrm{P}_{1 \text {-butene }}=5 \mathrm{mbar}$ and $\mathrm{P}_{\mathrm{H} 2}=3.7$ mbar with a standard surface concentration of $\theta^{\circ}=0.5$. For the hydrogenation of $\mathbf{1}$ to butane $\mathbf{9}$, we use 1-butene $\mathbf{1}$ and $\mathrm{H}_{2}$ as free energy reference. This transformation starts with a hydrogenation to 2-butyl 8; see Fig. 1. In the final step of each reaction path, the product, 2-butene $\mathbf{2}$ or butane $\mathbf{9}$, respectively, is desorbed into the gas phase. The free energy of $\mathbf{9}^{\star}$ is shifted, by $-40 \mathrm{~kJ} \mathrm{~mol}^{-1}$ from the DFT model results. This empirical correction reflects the challenging nature of modeling such processes by the DFT methodology applied; for details, see the text. This correction is inspired by experimental data on the typical entropy loss during the adsorption, from the gas, of saturated hydrocarbons on late transition metal surfaces.

The free energies in the following are calculated for $373 \mathrm{~K}$ and $100 \mathrm{kPa}$, mimicking experimental conditions. According to the DFT-derived free energy profiles of the lowest energy pathways for all surfaces, Fig. 5, the reaction barriers of 1-butene isomerization $\left(\mathbf{1}^{*} \rightarrow \mathbf{5}^{*} \rightarrow \mathbf{2}^{*}\right)$ are lower than the barriers to hydrogenation $\left(\mathbf{1}^{*} \rightarrow \mathbf{8}^{*} \rightarrow \mathbf{9}^{*}\right)$, thus rationalizing the experimentally determined preference for the isomerization. Adsorption energies from the gas phase range from slightly endothermic to somewhat exothermic for the overall hydrogenation, see also Supplementary Table S1 of the SI. For the hydrogenation path, hydrogen adsorption, formally $1 / 2 \mathrm{H}_{2}$ at infinite separation from $1^{*}$ and subsequent rearrangement, lowers the reaction energy of the initial step, Fig. 5. Furthermore, the isomerization shows a weak structure sensitivity (slightly lower barriers for the rougher surfaces), in agreement with the experimental results that isomerization is nearly independent of the particle size. In contrast, the hydrogenation of 1-butene exhibits a pronounced structure sensitivity, with $\operatorname{Pd}(111)$ clearly having the lowest barriers of all surfaces examined. In consequence, the hydrogenation of 1-butene is more efficient on Pd NPs larger than $4 \mathrm{~nm}$, because these particles feature well-developed and abundant (111) facets ${ }^{47}$. The specific role of the (111) facets can be understood based on the particular reaction energy for the conversion of 1-butene $\mathbf{1}^{*}$ to butyl $\mathbf{8}^{*}$, see below and Fig. 5. Note that the energy difference between $\mathbf{1}^{*}$ and $\mathbf{8}^{*}$ is calculated at $\sim 50 \mathrm{~kJ} \mathrm{~mol}^{-1}$ for the surfaces (110), (100), and (211), but only $18 \mathrm{~kJ} \mathrm{~mol}^{-1}$ for (111). This difference in reaction energy translates to the barrier $\mathbf{1}^{*} \rightarrow \mathbf{8}^{*}$, being by at least $20 \mathrm{~kJ} \mathrm{~mol}^{-1}$ lower for (111) compared to other facets studied, Fig. 5 and
Supplementary Table S2 of the SI. Already previous computational work determined a notably more favorable adsorption energy, $110 \mathrm{~kJ} \mathrm{~mol}^{-1}$, for butane at $\mathrm{Pd}(100)$ compared to $\operatorname{Pd}(111)$, $70 \mathrm{~kJ} \mathrm{~mol}^{-1} 56$.

Turning to the DFT modeling results for the isomerization of 1 - $1^{*}$ to 2 -butene $2^{*}$, we focus on the conversion to trans-butene, keeping in mind that cis-butene will be formed in analogous fashion ${ }^{9}$. On all Pd surfaces studied, the isomerization of $\mathbf{1}^{*}$ to $\mathbf{2}^{*}$ is found to proceed preferentially in a two-step mechanism, via initial dehydrogenation to $5^{*}$ and subsequent hydrogenation to $2^{*}$, Fig. 1 . The calculated barriers for the latter reactions on the closed-packed surface $\operatorname{Pd}(111)$ are rather high, with $G_{\mathrm{a}}\left(\mathbf{1}^{*} \rightarrow \mathbf{5}^{*}\right)=32 \mathrm{~kJ} / \mathrm{mol}$ and $G_{\mathrm{a}}\left(\mathbf{5}^{*} \rightarrow \mathbf{2}^{*}\right)=70 \mathrm{~kJ} / \mathrm{mol}$, Fig. 5 . The initial step is slightly exergonic, by $-26 \mathrm{~kJ} / \mathrm{mol}$, while the hydrogenation to $2^{*}$ is slightly endergonic, by $30 \mathrm{~kJ} / \mathrm{mol}$. Overall, the reaction energy of the isomerization over $\operatorname{Pd}(111)$ is $4 \mathrm{~kJ} / \mathrm{mol}$, i.e., the reaction is essentially thermoneutral. Note that on the surfaces $\operatorname{Pd}(100), \operatorname{Pd}(110)$, and $\operatorname{Pd}(211)$ the free energy barriers of the dehydrogenation of $\mathbf{1}^{*}$ to $5^{*}$ are reduced to $22 \mathrm{~kJ} / \mathrm{mol}, 25 \mathrm{~kJ} /$ $\mathrm{mol}$, and $14 \mathrm{~kJ} / \mathrm{mol}$, respectively. The associated reaction free energies $\Delta G_{\mathrm{r}}\left(\mathbf{1}^{*} \rightarrow \mathbf{5}^{*}\right),-29 \mathrm{~kJ} / \mathrm{mol},-35 \mathrm{~kJ} / \mathrm{mol}$, and $-27 \mathrm{~kJ} / \mathrm{mol}$, respectively, on these surfaces are also lower than the one calculated for $\operatorname{Pd}(111)$, thus promoting the dehydrogenation of $\mathbf{1}^{*}$ to $5^{*}$. The extremely low barriers of $1^{*} \rightarrow 5^{*}$ are followed by relatively high barriers for the formation of $2^{*}$, with $\Delta G_{\mathrm{a}}\left(5^{*} \rightarrow \mathbf{2}^{*}\right)$ calculated at $73 \mathrm{~kJ} / \mathrm{mol}, 67 \mathrm{~kJ} / \mathrm{mol}$, and $58 \mathrm{~kJ} / \mathrm{mol}$ for $\mathrm{Pd}(100)$, $\operatorname{Pd}(110)$ and $\operatorname{Pd}(211)$, respectively, Fig. 5. The somewhat lower barriers for the latter two surfaces, representing the small particles with rougher surfaces, may help to rationalize the slightly improved isomerization activity (TOF) of defective small $\mathrm{Pd}$ NPs compared to larger NPs.

An alternative path for the isomerization of 1-butene $\mathbf{1}^{*}$ on Pd catalysts proceeds via an initial hydrogenation reaction $\mathbf{1}^{*} \rightarrow \mathbf{8}^{*}$ to form $8^{*}$, followed by the dehydrogenation $8^{*} \rightarrow 2^{*}$; see 1 and Supplementary Fig. 1 of the SI. This pathway is known as the Horiuti-Polanyi mechanism ${ }^{7,8}$. Compared to the isomerization pathway via $5^{*}$, the path to $2^{*}$ via $8^{*}$ is calculated notably more favorable for $\operatorname{Pd}(111)$, but not for the other surfaces examined. The corresponding free energy barriers were determined at $57 \mathrm{~kJ} \mathrm{~mol}^{-1}$ and $56 \mathrm{~kJ} \mathrm{~mol}^{-1}$, whereas the free energy barrier for $\mathbf{5}^{*} \rightarrow \mathbf{2}^{*}$ amounts to $70 \mathrm{~kJ} \mathrm{~mol}^{-1}$ for $\operatorname{Pd}(111)$. Barriers for $\mathbf{1}^{*} \rightarrow \mathbf{8}^{*}$ on the surfaces $\operatorname{Pd}(100), \operatorname{Pd}(110)$ and $\operatorname{Pd}(211)$ were calculated in the range $77-83 \mathrm{~kJ} / \mathrm{mol}$, somewhat higher than the route via $5^{*}$, Fig. 5. Moreover, the formation of $\mathbf{8}^{*}$ from $\mathbf{1}^{*}$ on $\operatorname{Pd}(100)$, $\operatorname{Pd}(110)$ and $\operatorname{Pd}(211)$ was determined highly endergonic, by $\sim 50 \mathrm{~kJ} / \mathrm{mol}$. Overall, the Horiuti-Polanyi mechanism is less relevant for the catalyst under study, due to the endergonicity of $\mathbf{1}^{*} \rightarrow \mathbf{8}^{*}$ for all surfaces studied, rendering the absolute barrier of $\mathbf{8}^{*} \rightarrow \mathbf{2}^{*}$ higher than the barrier of $5^{*} \rightarrow \mathbf{2}^{*}$.

Two alternative pathways also exist for the hydrogenation of 1-butene $\mathbf{1}^{*}$ to -butane $9^{*}$, namely initial hydrogenation steps via either $\mathbf{1}^{*} \rightarrow \mathbf{8}^{*}$ to 2 -butyl $\mathbf{8}^{*}$ or $\mathbf{1}^{*} \rightarrow \mathbf{7}^{*}$ to 1 -butyl $\mathbf{7}^{*}$, Fig. 1 . On $\operatorname{Pd}(111)$, reaction $\mathbf{1}^{*} \rightarrow \mathbf{8}^{*}$ has a lower barrier than $\mathbf{1}^{*} \rightarrow \mathbf{7}^{*}$, $57 \mathrm{~kJ} \mathrm{~mol}^{-1}$ vs $72 \mathrm{~kJ} \mathrm{~mol}^{-1}$, respectively. On $\mathrm{Pd}(110)$, the two alternative initial hydrogenation steps are calculated nearly degenerate, whereas for $\operatorname{Pd}(100)$ and $\operatorname{Pd}(211) \mathbf{1}^{*} \rightarrow 7^{*}$ is preferred by $7 \mathrm{~kJ} \mathrm{~mol}^{-1}$ and $9 \mathrm{~kJ} \mathrm{~mol}^{-1}$, respectively. As for the second hydrogenation step on these pathways, for all Pd surfaces explored, reaction $\mathbf{8}^{*} \rightarrow \mathbf{9}^{*}$ exhibits a similar or slightly lower barrier than reaction $\mathbf{7}^{*} \rightarrow 9^{*}$, but is less exergonic than the latter. Unlike the other free energy values, that of butane $9^{*}$ is a special case as the harmonic oscillator model severely overestimates the entropy loss upon adsorption. From experiments on butane over $\operatorname{Pt}(111)^{57}$, one derives a substantially lower entropy contribution to the desorption free energy, $-34 \mathrm{~kJ} \mathrm{~mol}^{-1}$, for a monolayer coverage at $383 \mathrm{~K}$. Based on this experimental result ${ }^{57}$, we applied 
a correction, $-40 \mathrm{~kJ} \mathrm{~mol}^{-1}$, to the DFT free energy results of $\mathbf{9}^{*}$ for all Pd surfaces under study. At $373 \mathrm{~K}$, adsorbed butane $9^{*}$ will immediately desorb into the gas phase, not engaging in any reverse reaction. In any case, the free energy state of $\mathbf{9}^{*}$, corrected with suitable experiments in mind, will affect neither the rate $\mathbf{1} \rightarrow \mathbf{9}$ nor the selectivity of $\mathbf{2}$ vs. $\mathbf{9}$ in the kinetic modeling. Note that the calculated free energy for the net gas phase reaction $\mathbf{1} \rightarrow \mathbf{9},-85 \mathrm{~kJ}$ $\mathrm{mol}^{-1}$, agrees within $5 \mathrm{~kJ} \mathrm{~mol}^{-1}$ with the experimental value $\mathrm{e}^{58,59}$.

In the following, we inspect the pathways $1^{*} \rightarrow 5^{*} \rightarrow 2^{*}$ and $\mathbf{1}^{*} \rightarrow \mathbf{8}^{*} \rightarrow \mathbf{9}^{*}$ in more detail, as they provide a rather representative view on the barriers. Figure 5 summarizes the lowest free energy profiles of the isomerization, $1^{*} \rightarrow 5^{*} \rightarrow 2^{*}$, and the hydrogenation, $\mathbf{1}^{*} \rightarrow \mathbf{8}^{*} \rightarrow \mathbf{9}^{*}$, as calculated for the Pd surfaces (111), (100), (110), and (211). The dehydrogenation of $\mathbf{1}^{*}$ to $5^{*}$ is clearly preferred to the hydrogenation forming $8^{*}$. Therefore, the isomerization reaction is modeled as more favorable on all $\mathrm{Pd}$ particles. This observation is in close agreement with the high isomerization/hydrogenation ratios, irrespective of the $\mathrm{Pd}$ particle size. Interestingly, the lowest hydrogenation barriers are calculated for the close-packed surface $\operatorname{Pd}(111)$, while the surfaces $\operatorname{Pd}(110)$ and $\operatorname{Pd}(211)$ exhibit higher barriers, i.e., the hydrogenation seems to be rare on these corrugated surfaces. The lowest lying intermediate $5^{*}$ does not bind as strongly on $\operatorname{Pd}(111)$ as an the other surfaces, concomitant with the relatively moderate barrier height for hydrogenation, overall yielding a higher propensity for butane formation than the other surfaces considered. At the other end of the selectivity ratio, $\operatorname{Pd}(211)$ binds intermediate $5^{*}$ strongest, but also exhibits the lowest barrier to isomerization, while hydrogenation remains challenging.

By appealing to the similarity between these stepped surfaces and the surface of rough particles, we thus are able to rationalize the experimental observations. Furthermore, the desorption of the fully hydrogenated product $n$-butane is an exergonic process for all Pd surfaces and it is expected to be most facile on $\mathrm{Pd}(111)$. For the isomerization product, at $373 \mathrm{~K}$ the desorption from $\mathrm{Pd}(111)$ is exergonic by $-27 \mathrm{~kJ} \mathrm{~mol}^{-1}$, Supplementary Table 1. The desorption of trans-2-butene is exergonic on $\mathrm{Pd}(100),-9 \mathrm{~kJ}$ $\mathrm{mol}^{-1}$, and somewhat endergonic on the surfaces $\mathrm{Pd}(110)$ and $\mathrm{Pd}(211)$, by $5 \mathrm{~kJ} \mathrm{~mol}^{-1}$ and $15 \mathrm{~kJ} \mathrm{~mol}^{-1}$, respectively. Note that Fig. 5 depicts a $1 / 2 \mathrm{ML} \mathrm{H}$ coverage situation where the energy of $2^{*}$ is calculated $10 \mathrm{~kJ} \mathrm{~mol}^{-1}$ more positive than at $1 / 16 \mathrm{ML} \mathrm{H}$ coverage 9 . Compared to 1-butene, the desorption of trans-2butene is preferred by at least $10 \mathrm{~kJ} \mathrm{~mol}^{-1}$. A difference in DFT adsorption energies of $18 \mathrm{~kJ} \mathrm{~mol}^{-1}$ was previously determined on $\operatorname{Pd}(111)^{60}$. As expected, the desorption of butane from all surfaces is very exergonic. In a further modeling step, using the DFT results, we carried out microkinetic simulations for reaction conditions with 3.7 mbar $\mathrm{H}_{2}$ pressure to model the product distributions vs. time and compare them to the experiments, see Fig. 6 and Supplementary Notes 1 and 2 of the SI. This $\mathrm{H}_{2}$ pressure was shown to reproduce the experimental conversion rates for the single crystal surfaces $\operatorname{Pd}(111)$ and $\operatorname{Pd}(110)$ and thus was also applied herein ${ }^{9}$.

As demonstrated in Fig. 6a, the selectivity ratio and the rates on large faceted Pd NPs were well-mimicked by combining the results for (111), (100) and (211) surfaces in a 60:20:20\% ratio (with (211) representing edge sites), according to typical distributions of surface atoms in the NP size range of $4-8 \mathrm{~nm}^{24,38,47}$. The closed packed $\operatorname{Pd}(111)$ surface allows hydrogenation, while $\operatorname{Pd}(100)$ and $\operatorname{Pd}(211)$ preferentially lead to isomerization Fig. $6 \mathrm{~b}$ shows the corresponding simulation for small/rough $\mathrm{Pd}$ nanoparticles. Model results for $\mathrm{Pd}(211)$, $\mathrm{Pd}(110)$, and $\mathrm{Pd}(100)$ in a 60:20:20\% relation again reproduce well the selectivity ratio and rates. The $\mathrm{Pd}(110)$ patches still allow
Product distribution (\%)
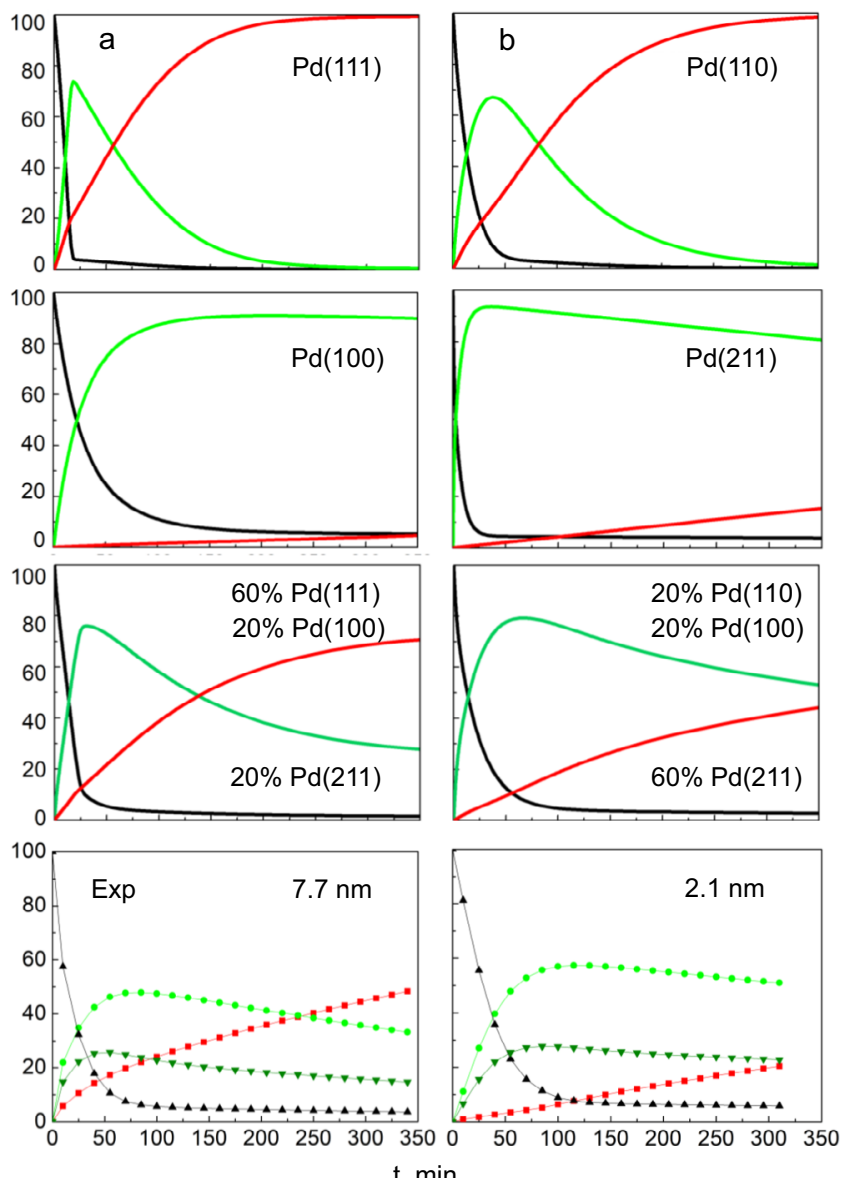

Fig. 6 Simulated product distribution of 1-butene isomerization and hydrogenation as a function of the reaction time at $\mathbf{3 7 3} \mathrm{K}$. For a $\mathrm{Pd}(111)$, $\mathrm{Pd}(100)$, the mixture $60 \% \mathrm{Pd}(111) / 20 \% \mathrm{Pd}(100) / 20 \% \mathrm{Pd}(211)$, and, at the bottom, the corresponding experimental results for average Pd NPs of $7.7 \mathrm{~nm}$. b Analogous reactions simulated for $\mathrm{Pd}(110), \operatorname{Pd}(211)$, the mixture $60 \% \mathrm{Pd}(211) / 20 \% \mathrm{Pd}(110) / 20 \% \mathrm{Pd}(100)$, and the corresponding experimental results for average Pd NPs of $2.1 \mathrm{~nm}$. Color coding: black-1butene, red-n-butane, light green-trans-2-butene, dark green-cis-2butene.

hydrogenation, whereas the isomerization is mainly carried out on $\operatorname{Pd}(211)$ and $\operatorname{Pd}(100)$ patches. The hydrogenation reaction becomes notable only when the accumulated 2-butene 2 readsorbs on the surface. Given the various kinds of approximations and the typical error bar of $\sim 10 \mathrm{~kJ} \mathrm{~mol}^{-1}$ for barrier predictions by DFT calculations ${ }^{61}$, the experimental catalytic performance is well reproduced (marked as inverted triangles in Fig. 4). The sensitivity to the quantitative combination of facets was probed using, among others, the alternative ratios 60/ $40 \mathrm{Pd}(111) / \mathrm{Pd}(100)$ for large particles and $70 / 30 \mathrm{Pd}(211) / \mathrm{Pd}(110)$ for small particles; see Supplementary Fig. 20 of the SI.

To verify experimentally that the hydrogenation of 1-butene mainly depends on the availability of (111) and (110) patches in the NP surface, an additional model catalyst was prepared that exhibits Pd NPs of $4.4 \mathrm{~nm}$ mean size (Fig. $2 \mathrm{~b}$ and empty markers in Fig. 4). The average particle size of this sample is similar to that of the $5.3 \mathrm{~nm} \mathrm{Pd}$ catalysts, but there were 3.6-times more nanoparticles $/ \mathrm{cm}^{2}$ and 2.4-times more Pd surface atoms for the $4.4 \mathrm{~nm}$ catalyst. Accordingly, the overall conversion was larger, but the $4.4 \mathrm{~nm}$ NPs exhibited a similar selectivity ratio for 
n-butane as the $5.3 \mathrm{~nm}$ NPs, despite being prepared according to the procedure for the small rough NPs, i.e., at low substrate temperature. However, as shown by infrared spectra of adsorbed $\mathrm{CO}^{45}$, in this size range also particles with a "nominally rougher" surface develop better ordered facets. Accordingly, also the $4.4 \mathrm{~nm}$ Pd NPs offer low-index surface facets and thus exhibit a similar selectivity ratio for $n$-butane as the $5.3 \mathrm{~nm}$ NPs. The TOF values for hydrogenation are rather similar to those of larger particles, see the empty markers and arrows in Fig. 4a. In a temperature programmed reaction (TPR) study ${ }^{23}$ of trans-2pentene hydrogenation in UHV, the activity was also assigned to (111) facets. On the other hand, for the $4.4 \mathrm{~nm} \mathrm{NPs,} \mathrm{we} \mathrm{did}$ determine a yield of the isomerization product that is close to that of the "rougher" particles, making the $4.4 \mathrm{~nm} \mathrm{NPs}$ a special "hybrid" case, see Fig. 2b. Accordingly, with our modeling effort, we were able to rationalize the particle size effect in atmospheric pressure 1-butene isomerization and hydrogenation on $\mathrm{Pd} / \mathrm{Al}_{2} \mathrm{O}_{3}$ catalysts in an almost quantitative fashion.

\section{Discussion}

We combined UHV-grown model catalysts (mean Pd particle size of $2-8 \mathrm{~nm}$ ), atmospheric pressure batch reactor activity and selectivity studies, as well as DFT model results and microkinetic modeling for the Pd surfaces (111), (100), (110), and (211). All four surfaces exhibit low calculated barriers for isomerization, rationalizing the preference for isomerization and its weak particle size dependence. At variance, the higher barriers for hydrogenation show a strong structure sensitivity with the (111) surface (or such patches on NPs) exhibiting the lowest barriers.

Our modeling results suggest that, for all surfaces studied, the isomerization of 1-butene proceeds via an initial dehydrogenation of $1^{*}$, i.e., the removal of the allylic hydrogen, followed by a hydrogenation of the intermediate $5^{*}$. Our calculations also show that the first hydrogenation step, forming the intermediate 2-butyl $\mathbf{8}^{*}$, governs the hydrogenation of $\mathbf{1}^{*}$ and they confirm that this alkyl intermediate is crucial on $\operatorname{Pd}(111), \operatorname{Pd}(100)$, $\operatorname{Pd}(110)$ and $\operatorname{Pd}(211)$.

With these modeling results, one is able to rationalize in full the particle size dependence of 1-butene isomerization vs. hydrogenation. We conclude from this work that isomerization is achieved by small, rough NPs, that have no extended amounts of $\mathrm{Pd}(111)$ patches, whereas larger Pd nanoparticles (with their surface dominated by (111) facets) show higher rates for hydrogenation. Indeed, the size and amount of (111) surface patches, exhibited by larger particles, allow full hydrogenation of butene to butane. Microkinetic modeling demonstrated that isomerization usually precedes hydrogenation, with 2 -butene being released to the gas-phase before it is re-adsorbed and converted to butane. This sequential reactivity could be further exploited for even improved selectivity.

In the current case, we were able to model indeed the properties of $\mathrm{Pd}$ nanoparticles via the properties of their individual surface facets and edge sites, which is the fundamental rationale of the surface-science single-crystal approach to heterogeneous catalysis. Clearly, this strategy does not apply to cases where other effects are active, may they be related to the electronic structure, metal/support interactions or inter-facet (intraparticle) interactions. Yet, the new insight presented may lead to an improved understanding and control of the selectivity of technologically relevant Pd catalysts.

\section{Methods}

Catalyst preparation. The experiments were carried out in an ultrahigh vacuum (UHV; base pressure $\sim 1 \times 10^{-10} \mathrm{mbar}$ ) surface analysis system combined with a UHV-high pressure reaction cell ${ }^{47,52} . \mathrm{Pd} / \mathrm{Al}_{2} \mathrm{O}_{3}$ model catalysts, with a mean $\mathrm{Pd}$ particle size from $2 \mathrm{~nm}$ to $8 \mathrm{~nm}$, were prepared by physical vapor deposition of $\mathrm{Pd}$ on a thin $\mathrm{Al}_{2} \mathrm{O}_{3}$ film $(\sim 0.5 \mathrm{~nm})$ grown on clean $\mathrm{NiAl}(110)^{38-40}$. Samples were transferred under UHV to the reaction cell, where catalytic re-circulated batch measurements were performed at atmospheric pressure $\left(\mathrm{P}_{1 \text {-butene }}: 5\right.$ mbar; $\mathrm{P}_{\mathrm{H} 2}: 10$ mbar; Ar added to 1 bar) at $373 \mathrm{~K}$, with reaction products quantified by on-line gas chromatography (GC).

Computational details. We carried out plane-wave based DFT calculations using the Vienna ab-initio simulation package (VASP) ${ }^{62,63}$. We applied the generalized gradient approximation (GGA) as proposed by Perdew, Burke, and Ernzerhof (PBE) as exchange-correlation functional ${ }^{55,64}$. We used the projector-augmented wave (PAW) method to describe ionic cores ${ }^{65,66}$. The cutoff energy for the planewave basis set was $400 \mathrm{eV}$. A first-order Methfessel-Paxton smearing with a width of $0.1 \mathrm{eV}$ was applied ${ }^{67}$. A Monkhorst-Pack mesh of $5 \times 5 \times 1 k$ points was used to sample the Brillouin zone. Geometries were considered converged when the force on each atom was below $2 \times 10^{-4} \mathrm{eV} \mathrm{pm}^{-1}$.

More details on catalyst preparation, characterization methods, catalytic data, and modeling are described in the Supplementary Information. This material is available free of charge via the Internet.

Reporting summary. Further information on research design is available in the Nature Research Reporting Summary linked to this article.

\section{Data availability}

The Cartesian coordinates of intermediates and transition states generated in this study have been deposited at Gitlab under https://gitlab.com/agenest/pd-particles. Any other data that support the findings of this study are available from the corresponding author upon reasonable request.

Received: 25 March 2021; Accepted: 1 October 2021; Published online: 20 October 2021

\section{References}

1. Schimpf, S., Gaube, J. \& Claus, P. Selective hydrogenation of multiple unsaturated compounds. In Basic Principles in Applied Catalysis (ed. Baerns, M.) vol. 75, 85-123 (Springer, 2004).

2. Beck, J. S. et al. Organic reactions: sections 4.1-4.4. In Handbook of heterogeneous catalysis (eds Ertl, G., Knözinger, H. \& Weitkamp, J.) 2123-2231 (Wiley-VCH, 1997).

3. Torres Galvis, H. M. \& de Jong, K. P. Catalysts for production of lower olefins from synthesis gas: a review. ACS Catal. 3, 2130-2149 (2013).

4. Zacharopoulou, V. \& Lemonidou, A. Olefins from biomass intermediates: a review. Catalysts 8, 2-19 (2017).

5. Bond, G. C. Metal-catalysed reactions of hydrocarbons. (Kluwer Academic/ Plenum Publishers, 2005).

6. Obenaus, F., Droste, W., Neumeister, J. \& Neumeister, J. Butenes. In Ullmann's Encyclopedia of Industrial Chemistry (Wiley-VCH, 2000).

7. Horiuti, I. \& Polanyi, M. Exchange reactions of hydrogen on metallic catalysts. Trans. Faraday Soc. 30, 1164-1172 (1934).

8. Mattson, B. et al. Heterogeneous catalysis: the Horiuti-Polanyi mechanism and alkene hydrogenation. J. Chem. Educ. 90, 613-619 (2013).

9. Markova, V. K. et al. Catalytic transformations of 1-butene over palladium. a combined experimental and theoretical study. ACS Catal. 8, 5675-5685 (2018).

10. Heiz, U., Sanchez, A., Abbet, S. \& Schneider, W.-D. Catalytic oxidation of carbon monoxide on monodispersed platinum clusters: each atom counts. $J$. Am. Chem. Soc. 121, 3214-3217 (1999).

11. Crampton, A. S. et al. Ethylene hydrogenation on supported $\mathrm{Ni}, \mathrm{Pd}$ and $\mathrm{Pt}$ nanoparticles: catalyst activity, deactivation and the d-band model. J. Catal. 333, 51-58 (2016).

12. Abbet, S. et al. Nano-assembled Pd catalysts on $\mathrm{MgO}$ thin films. Thin Solid Films 400, 37-42 (2001).

13. Campbell, C. T. Ultrathin metal films and particles on oxide surfaces: structural, electronic and chemisorptive properties. Surf. Sci. Rep. 27, 1-111 (1997).

14. Bell, A. T. The impact of nanoscience on heterogeneous catalysis. Science 299, 1688-1691 (2003)

15. Liu, L. \& Corma, A. Metal catalysts for heterogeneous catalysis: from single atoms to nanoclusters and nanoparticles. Chem. Rev. 118, 4981-5079 (2018).

16. Yudanov, I. V., Genest, A., Schauermann, S., Freund, H.-J. \& Rösch, N. Size dependence of the adsorption energy of CO on metal nanoparticles: a DFT search for the minimum value. Nano Lett. 12, 2134-2139 (2012).

17. Yudanov, I. V. et al. CO adsorption on Pd nanoparticles: density functional and vibrational spectroscopy studies. J. Phys. Chem. B 107, 255-264 (2003). 
18. Kleis, J. et al. Finite size effects in chemical bonding: from small clusters to solids. Catal. Lett. 141, 1067-1071 (2011).

19. Posada-Borbón, A., Heard, C. J. \& Grönbeck, H. Cluster size effects in ethylene hydrogenation over palladium. J. Phys. Chem. C. 121, 10870-10875 (2017).

20. Yoon, C., Yang, M. X. \& Somorjai, G. A. Reactions of 1-butene and cis-2butene on platinum surfaces: structure sensitivity of cis-2-butene isomerization. J. Catal. 176, 35-41 (1998).

21. Ma, Z. \& Zaera, F. Organic chemistry on solid surfaces. Surf. Sci. Rep. 61, 229-281 (2006).

22. Shaikhutdinov, S. et al. Structure-reactivity relationships on supported metal model catalysts: adsorption and reaction of ethene and hydrogen on $\mathrm{Pd} /$ $\mathrm{Al}_{2} \mathrm{O}_{3} / \mathrm{NiAl}(110)$. J. Catal. 200, 330-339 (2001).

23. Doyle, A. M., Shaikhutdinov, S. K. \& Freund, H.-J. Surface-bonded precursor determines particle size effects for alkene hydrogenation on palladium. Angew. Chem. Int. Ed. 44, 629-631 (2005).

24. Silvestre-Albero, J., Rupprechter, G. \& Freund, H. Atmospheric pressure studies of selective 1,3-butadiene hydrogenation on well-defined $\mathrm{Pd} / \mathrm{Al}_{2} \mathrm{O}_{3} /$ $\mathrm{NiAl}(110)$ model catalysts: Effect of Pd particle size. J. Catal. 240, 58-65 (2006).

25. Wilde, M. et al. Influence of carbon deposition on the hydrogen distribution in $\mathrm{Pd}$ nanoparticles and their reactivity in olefin hydrogenation. Angew. Chem. Int. Ed. 47, 9289-9293 (2008).

26. Brandt, B. et al. Isomerization and hydrogenation of cis-2-butene on Pd model catalyst. J. Phys. Chem. C. 112, 11408-11420 (2008).

27. Brandt, B. et al. Conversion of cis- and trans-2-butene with deuterium on a $\mathrm{Pd} / \mathrm{Fe}_{3} \mathrm{O}_{4}$ model catalyst. J. Catal. 265, 191-198 (2009).

28. Calle-Vallejo, F., Martínez, J. I., García-Lastra, J. M., Sautet, P. \& Loffreda, D. Fast prediction of adsorption properties for platinum nanocatalysts with generalized coordination numbers. Angew. Chem. Int. Ed. 53, 8316-8319 (2014).

29. Calle-Vallejo, F. et al. Finding optimal surface sites on heterogeneous catalysts by counting nearest neighbors. Science 350, 185-189 (2015).

30. Jørgensen, M. \& Grönbeck, H. First-principles microkinetic modeling of methane oxidation over $\mathrm{Pd}(100)$ and $\mathrm{Pd}(111)$. ACS Catal. 6, 6730-6738 (2016).

31. Jørgensen, M. \& Grönbeck, H. The site-assembly determines catalytic activity of nanoparticles. Angew. Chem. Int. Ed. 57, 5086-5089 (2018).

32. Jørgensen, M. \& Grönbeck, H. Perspectives on computational catalysis for metal nanoparticles. ACS Catal. 9, 8872-8881 (2019).

33. Decarolis, D., Lezcano-Gonzalez, I., Gianolio, D. \& Beale, A. M. Effect of particle size and support type on Pd catalysts for 1,3-butadiene hydrogenation. Top. Catal. 61, 162-174 (2018).

34. Markov, P. V. et al. Experimental and theoretical analysis of particle size effect in liquid-phase hydrogenation of diphenylacetylene. Chem. Eng. J. 404, 126409 (2021).

35. Freund, H.-J. Adsorption of gases on complex solid surfaces. Angew. Chem Int. Ed. Engl. 36, 452-475 (1997).

36. Freund, H.-J. Clusters and islands on oxides: from catalysis via electronics and magnetism to optics. Surf. Sci. 500, 271-299 (2002).

37. Bäumer, M. et al. The Growth and properties of Pd and Pt on $\mathrm{Al}_{2} \mathrm{O}_{3}$ / NiAl(110). Ber. Bunsenges. F.ür. Phys. Chem. 99, 1381-1386 (1995).

38. Bäumer, M. \& Freund, H.-J. Metal deposits on well-ordered oxide films. Prog. Surf. Sci. 61, 127-198 (1999).

39. Libuda, J. \& Freund, H.-J. Molecular beam experiments on model catalysts. Surf. Sci. Rep. 57, 157-298 (2005).

40. Freund, H.-J. et al. Preparation and characterization of model catalysts: from ultrahigh vacuum to in situ conditions at the atomic dimension. J. Catal. 216, 223-235 (2003).

41. Meusel, I. et al. The interaction of oxygen with alumina-supported palladium particles. Catal. Lett. 71, 5-13 (2001).

42. Heemeier, M. et al. On the thermal stability of metal particles supported on a thin alumina film. Surf. Sci. 523, 103-110 (2003).

43. Hansen, K. H. et al. Palladium nanocrystals on $\mathrm{Al}_{2} \mathrm{O}_{3}$ : Structure and adhesion energy. Phys. Rev. Lett. 83, 4120-4123 (1999).

44. Shaikhutdinov, S. H. et al. Interaction of oxygen with palladium deposited on a thin alumina film. Surf. Sci. 501, 270-281 (2002).

45. Wolter, K., Seiferth, O., Kuhlenbeck, H., Bäumer, M. \& Freund, H.-J. Infrared spectroscopic investigation of $\mathrm{CO}$ adsorbed on Pd aggregates deposited on an alumina model support. Surf. Sci. 399, 190-198 (1998).

46. Dellwig, T., Rupprechter, G., Unterhalt, H. \& Freund, H.-J. Bridging the pressure and materials gaps: high pressure sum frequency generation study on supported Pd nanoparticles. Phys. Rev. Lett. 85, 776-779 (2000).

47. Rupprechter, G. Sum frequency generation and polarization-modulation infrared reflection absorption spectroscopy of functioning model catalysts from ultrahigh vacuum to ambient pressure. Adv. Catal. 51, 133-263 (2007).
48. Bertarione, S. et al. Surface reactivity of Pd nanoparticles supported on polycrystalline substrates as compared to thin film model catalysts: infrared study of CO adsorption. J. Phys. Chem. B 108, 3603-3613 (2004).

49. Lear, T. et al. The application of infrared spectroscopy to probe the surface morphology of alumina-supported palladium catalysts. J. Chem. Phys. 123, 174706-174706 (2005).

50. Borchert, $\mathrm{H}$. et al. Pd nanoparticles with highly defined structure on $\mathrm{MgO}$ as model catalysts: An FTIR study of the interaction with $\mathrm{CO}, \mathrm{O} 2$, and $\mathrm{H} 2$ under ambient conditions. J. Catal. 247, 145-154 (2007).

51. Zorn, $\mathrm{K}$. et al. $\mathrm{CO}$ oxidation on technological $\mathrm{Pd}-\mathrm{Al}_{2} \mathrm{O}_{3}$ catalysts: oxidation state and activity. J. Phys. Chem. C. 115, 1103-1111 (2011).

52. Rupprechter, G., Dellwig, T., Unterhalt, H. \& Freund, H.-J. CO adsorption on $\mathrm{Ni}(100)$ and $\mathrm{Pt}(111)$ studied by infrared-visible sum frequency generation spectroscopy: design and application of an SFG-compatible UHV-highpressure reaction cell. Top. Catal. 15, 19-26 (2001).

53. Chee, S. W., Arce-Ramos, J. M., Li, W., Genest, A. \& Mirsaidov, U. Structural changes in noble metal nanoparticles during $\mathrm{CO}$ oxidation and their impact on catalyst activity. Nat. Commun. 11, 21331-21339 (2020).

54. Suchorski, Y. et al. Resolving multifrequential oscillations and nanoscale interfacet communication in single-particle catalysis. Science 372, 1314-1318 (2021).

55. Perdew, J. P., Burke, K. \& Ernzerhof, M. Generalized gradient approximation made simple. Phys. Rev. Lett. 77, 3865-3868 (1996).

56. Chizallet, $\mathrm{C}$. et al. Thermodynamic stability of buta-1,3-diene and but-1-ene on $\mathrm{Pd}(111)$ and (100) surfaces under $\mathrm{H}_{2}$ pressure: a dft study. J. Phys. Chem. C. 115, 12135-12149 (2011).

57. Campbell, C. T. \& Sellers, J. R. V. The entropies of adsorbed molecules. J. Am. Chem. Soc. 134, 18109-18115 (2012).

58. Pitzer, K. S. Thermodynamics of gaseous hydrocarbons: ethane, ethylene, propane, propylene, n-butane, isobutane, 1-butene, cis and trans 2-butenes, isobutene, and neopentane (tetramethylmethane). J. Chem. Phys. 5, 15-21 (1937).

59. Haseli, Y. Interrelations between standard entropy, formation enthalpy and boiling temperature of hydrocarbons. Fuel 280, 118541 (2020).

60. Valcárcel, A., Clotet, A., Ricart, J. M., Delbecq, F. \& Sautet, P. Comparative DFT study of the adsorption of 1,3-butadiene, 1-butene and 2-cis/transbutenes on the $\operatorname{Pt}(111)$ and $\operatorname{Pd}(111)$ surfaces. Surf. Sci. 549, 121-133 (2004).

61. Mallikarjun Sharada, S., Bligaard, T., Luntz, A. C., Kroes, G.-J. \& Nørskov, J. K. SBH10: a benchmark database of barrier heights on transition metal surfaces. J. Phys. Chem. C. 121, 19807-19815 (2017).

62. Kresse, G. \& Hafner, J. Ab initio molecular-dynamics simulation of the liquidmetal-amorphous-semiconductor transition in germanium. Phys. Rev. B 49, 14251-14269 (1994).

63. Kresse, G. \& Furthmüller, J. Efficiency of ab-initio total energy calculations for metals and semiconductors using a plane-wave basis set. Comput. Mater. Sci. 6, 15-50 (1996)

64. Perdew, J. P., Burke, K. \& Ernzerhof, M. Perdew, Burke, and Ernzerhof reply. Phys. Rev. Lett. 80, 891-891 (1998).

65. Blöchl, P. E. Projector augmented-wave method. Phys. Rev. B 50, 17953-17979 (1994).

66. Kresse, G. \& Joubert, D. From ultrasoft pseudopotentials to the projector augmented-wave method. Phys. Rev. B 59, 1758-1775 (1999).

67. Methfessel, M. \& Paxton, A. T. High-precision sampling for Brillouin-zone integration in metals. Phys. Rev. B 40, 3616-3621 (1989).

\section{Acknowledgements}

We gratefully acknowledge financial support by the Austrian Science Fund (FWF; Single Atom Catalysis I4434-N; SFB FOXSI F4502-N16), MEC (Acciones Integradas HU2006002) and ÖAD (WTZ 12/2006). JSA acknowledges GV (BEST/2007/045) supporting research stays in Vienna. This work was supported by grants 1527700033, A19E9a0103 of the A*STAR Science and Engineering Research Council, as well as a generous allotment of computational resources at the A*STAR Computational Resource Center, the National Supercomputing Centre Singapore and the Vienna Scientific Cluster (VSC).

\section{Author contributions}

A.G. contributed to the interpretation and supervised the microkinetic modeling. J.S.-A. performed the experiments. W.Q.L. carried out the microkinetic modeling. A.G. and N.R. wrote the modeling part of the manuscript, J.S.-A. and G.R. wrote the experimental draft of the manuscript, which was finally revised by all authors. N.R. and G.R. acquired the funding and supervised the research.

\section{Competing interests}

The authors declare no competing interests. 


\section{Additional information}

Supplementary information The online version contains supplementary material available at https://doi.org/10.1038/s41467-021-26411-8.

Correspondence and requests for materials should be addressed to Günther Rupprechter.

Peer review information Nature Communications thanks Talat Shahnaz and the other, anonymous, reviewers for their contribution to the peer review of this work. Peer reviewer reports are available.

Reprints and permission information is available at http://www.nature.com/reprints

Publisher's note Springer Nature remains neutral with regard to jurisdictional claims in published maps and institutional affiliations. (c) (i) Open Access This article is licensed under a Creative Commons Attribution 4.0 International License, which permits use, sharing, adaptation, distribution and reproduction in any medium or format, as long as you give appropriate credit to the original author(s) and the source, provide a link to the Creative Commons license, and indicate if changes were made. The images or other third party material in this article are included in the article's Creative Commons license, unless indicated otherwise in a credit line to the material. If material is not included in the article's Creative Commons license and your intended use is not permitted by statutory regulation or exceeds the permitted use, you will need to obtain permission directly from the copyright holder. To view a copy of this license, visit http://creativecommons.org/ licenses/by/4.0/.

(C) The Author(s) 2021 